\title{
Estratégia Como Prática Na Segurança Pública: Um Estudo Etnográfico
}

\section{Strategy As A Practice In Public Security: An Ethnographic Study}

\author{
Duarte Raab Pires ${ }^{1}$, Lilian Soares Outtes Wanderley ${ }^{1}$
}

${ }^{1}$ Universidade Federal de Pernambuco, UFPE, Brasil.

Correspondência: Lilian Soares Outtes Wanderley. Av. Prof. Moraes Rego, 1235 - Cidade Universitária, Recife PE - CEP: 50670-901. Fone: +55 (81) 2126-8880. E-mail: 1.outtes@gmail.com.

Recebido: 25 de novembro de 2017 Aceito: 20 de abril de 2018 Publicado: 01 de maio de 2018

DOI: http://dx.doi.org/10.21714/1679-18272017v15n2.p564-575

\begin{abstract}
Resumo
Neste artigo, focamos em melhor entender percepções dos gestores policiais diante do processo de estratégia, como prática ocorrida na Polícia Rodoviária Federal - PRF, no período de instituição de seu primeiro Plano Estratégico, do início de 2014 até o final de 2016. O estudo foi realizado sob a tradição qualitativa, por meio da abordagem etnográfica, estruturado sob abordagem interpretativa de pesquisa social. A estruturação do trabalho etnográfico que viabilizou atingir os objetivos propostos, se deu por intermédio de uma coleta de dados primários como entrevistas semiestruturadas e observação participante, e secundários por meio da pesquisa documental. Os resultados apontam que, não obstante a pretensão dos gestores nacionais de valorizar o planejamento e a estrutura formal de gestão, os resultados têm sido alcançados por meio do empirismo e da adequação contextual. Todavia, foi o processo que lastreou essa adaptação, o qual foi capitaneado pela cultura organizacional e a influência axiológica de seus servidores, sem deixar de mencionar a própria natureza da atividade, vis-à-vis uma entrega adequada à sociedade, a qual se faz presente por intermédio do envolvimento da instituição com diversos stakeholders ou contrapartes.
\end{abstract}

Palavras-chave: Estratégia como prática; polícia rodoviária federal; segurança pública; governança em segurança pública; etnografia.

\begin{abstract}
In this paper, we focus on better understanding perceptions of police managers regarding the strategy process as a practice occurred in the Federal Highway Police (PRF), which occurred during the period of its first Strategic Plan, which was from the beginning of 2014 until the end of 2016. The study was carried out under the qualitative approach, through the ethnographic method, structured under the interpretive bias of social research. The structuring of the ethnographic work which made possible to achieve the proposed objectives was through a collection of primary data - semi-structured interviews and participant observation - and secondary - documentary research. The results show that, despite the intention of the national managers to value planning and the formal management structure, the results are achieved through empiricism and contextual adjustment. What is worth mentioning, however, is the process that backed this adaptation, captained by the organizational culture and the axiological influence of its servants, not to mention the very nature of the activity, vis-à-vis an adequate delivery to society, which is present through the involvement of the institution with its various stakeholders.
\end{abstract}

Keywords: Strategy as practice; federal highway police; public security; governance in public security; ethnography.

Esta obra está licenciada sob uma Licença Creative Commons Attribution 3.0.

\section{Introdução}

O processo de planejamento numa instituição corresponde à arena que de fato concretiza as decisões em nível estratégico, obviamente pautado e alicerçado no alcance dos objetivos pretendidos. Muito embora o planejamento seja um processo formal em uma série de organizações, não implica necessariamente em ser estruturado, claro, objetivo, portanto, não deixa de estar sujeito a diversas alterações, intempéries, adaptações, desde sua concepção 
à implementação final. As alterações ou mudanças do plano original à respectiva concretização, são medidas que buscam privilegiar o atingimento das metas estabelecidas e podem ser necessárias em razão de falhas de planejamento, inconsistências de dados, cenários imprevistos, limitações de recursos, cultura organizacional, relações de poder, entre outros. Freedman (2003) destaca que, ao se estabelecerem estratégias, não somente sua formulação é importante, mas, sobretudo, importa o cuidado na sua implementação para que se alcancem resultados sólidos ao longo do tempo. $\mathrm{O}$ autor acrescenta que para se implementar estratégias definidas, na maior parte das vezes, por exemplo, se fazem necessárias mudanças tecnológicas, organizacionais e comportamentais que afetam os indivíduos e a organização em um processo cíclico de mudança. Segundo Jarzabkowski (2005), é cada vez maior o foco de mais pesquisadores voltados a entender o processo estratégico, sua implementação, sua estruturação no dia-a-dia das organizações, em detrimento de seu conteúdo ou de sua forma. Nesse âmbito da estratégia como prática, essa é percebida como um fenômeno social, o que implicaria em dizer que se trata de um conjunto de práticas ou atividades humanas realizadas e não meramente um atributo organizacional (SCHATZKI, 2005; JARZABKOWSKI ET AL., 2007; VAARA \& WHITTINGTON, 2012; SEIDL \& WHITTINGTON, 2014).

O caso empírico escolhido para investigação foi o da Polícia Rodoviária Federal - PRF, que se trata de uma instituição policial federal, que conta com um efetivo formado por pouco mais de 10.000 mil policiais, todos concursados e com nível superior, subordinada ao Ministério da Justiça e presente em todo o território nacional. Sua estrutura conta com uma unidade administrativa central, a Sede Nacional, situada em Brasília, e Unidades Administrativas Regionais, representadas por 27 Superintendências, uma em cada UF e 05 (cinco) coordenações gerais nacionais, quais sejam: de Operações, Administrativa, Corregedoria, de Modernização e de Recursos Humanos. Além disso, é formada por 150 subunidades administrativas, denominadas Delegacias, e 413 Unidades Operacionais (UOPs), totalizando, assim, mais de 550 pontos de atendimento em todo o Brasil. A instituição apresentou seu primeiro planejamento estratégico em fevereiro de 2014 (BRASIL, 2014), pouco antes da Copa do Mundo de 2014, com um alcance inicial previsto até 2020.

Concernente ao público-alvo deste estudo, a alta gestão nacional e os superintendentes regionais foram selecionados, por serem os responsáveis tanto em nível nacional, quanto em nível estadual pela implementação estratégica. Ademais, esses gestores conhecem as especificidades e os detalhes das ações necessárias à gestão eficaz visando os objetivos pretendidos (PARES e VALLE, 2006). Cabe destacar que, por um lado os referidos gestores não receberam nenhuma preparação específica para a assunção das atividades de chefia, ou tampouco, participaram do processo de elaboração do Plano Plurianual ou do estabelecimento do Plano Estratégico da PRF (BRASIL, 2014) e por outro lado, a demanda por segurança pública de qualidade, por segurança-cidadã tem sido cada vez maior nos últimos anos (CIDH, 2009; RUIZ, 2014)

Nesse contexto empírico e teórico abordados, levantou-se a seguinte questão de pesquisa: " quais as percepções dos gestores da PRF diante do Plano Estratégico 2013-2020 (BRASIL, 2014)? ”. Para responder essa pergunta, foi realizada uma intervenção por meio de um estudo etnográfico com policiais rodoviários federais brasileiros, que atuam nacionalmente, conferindo especial atenção as suas práticas, discussões e implementações de ações, vis-àvis o planejamento estratégico. O principal interesse é entender de que modo os policiais gestores discutem e promulgam práticas de gestão para criar uma realidade que enquadre ou não o Plano Estratégico (BRASIL, 2014). Esta definição é relevante para o foco do estudo, uma vez que é o primeiro contato destes gestores com o tema planejamento estratégico, com um plano estratégico institucionalizado por via normativa (BRASIL, 2014) e com uma demanda crescente da sociedade.

A contribuição desse estudo pode ser destacada em dois pontos. Primeiro, empiricamente, os resultados apontam para o fato de que os gestores policiais rodoviários federais criaram uma estreita relação entre suas vidas particulares, a instituição em que trabalham e suas identidades, produzindo assim resultados baseados na demonstração de uma efetividade de resultados e não especificamente na atuação da gestão em si, sustentada pela dinâmica institucional. Em particular, é organização de cargo único, com atuação em nível nacional, com práticas compartilhadas de forma não institucionalizada em diversos estados e setores. Segundo, foi teorizado como o strategizing foi realizado e percebido nesse escopo policial específico. Mais amplamente, o estudo contribui com uma análise de processos específicos, por meio dos quais as ocupações, as inter-relações e o convívio social tanto influenciam quanto definem efetivamente situações de trabalho. Essas influências, cabe ressaltar, geram processos e meios dissociados dos pretendidos pela administração formal, em suas repetidas tentativas de padronizar habilidades e procedimentos de trabalho, não obstante que, aqueles que a compõem, não percebam ou não aceitem essa consciente ou discursivamente esse fato (PIRES, 2016).

A próxima seção expõe os fundamentos teóricos do estudo desenvolvendo um argumento relacionado ao da estratégia como prática, da tradução da língua inglesa Strategy as Practice - S-as-P. Em seguida, discute-se as 
posições metodológicas relacionadas à etnografia antes de introduzir os achados empíricos. Finalmente, extrai-se as principais contribuições do artigo na discussão e conclusão.

\section{Fundamentação Teórica}

\subsection{A Estratégia Como Prática - S-AS-P}

A estratégia organizacional é comumente associada à visão funcionalista, analisada por meio das abordagens clássica, evolucionária, sistêmica e processual (WHITTINGTON, 1996; 2002). As abordagens clássica, evolucionária e sistêmica definem que a estratégia é um recurso organizacional, seria algo que a organização possui. Segundo Johnson et al (2007) as organizações definem suas estratégias, quais sejam de diferenciação, de diversificação ou de associação, tendo processos de criação de planejamento estratégico, de decisão e de mudança organizacional, o que caracterizaria a estratégia como uma propriedade da organização. A abordagem processual, entretanto, não percebe que o planejamento seja indispensável à organização, pontuando que a estratégia poderia surgir e ser implementada por meio de um processo de aprendizado prático, de tal sorte que algum óbice ou erro num processo estratégico não levaria, necessariamente a uma desvantagem competitiva capaz de prejudicar severamente a organização (WHITTINGTON, 2002; MINTZBERG, 2008).

A abordagem processual, que propiciou o debate em Estratégia como Prática (S-as-P) (WHITTINGTON, 1996), direciona o foco dos estudos em estratégia para a ação do fazer estratégico. Cumpre destacar que esta corrente se apoia na base comportamental do sujeito, pautando-se em resultados observáveis para deduzir o conteúdo do fazer estratégico. Whittington (1996) traz uma abordagem alternativa para a estratégia, que se concentra numa perspectiva prática, destacando nesse contexto o praticante da estratégia e o processo de elaboração desta, entendendo a organização e a estratégia em si como partes subjacentes ou decorrentes das duas principais. Assim, essa nova abordagem de pesquisa sobre a estratégia, utiliza alguns conceitos da escola processual, entretanto, enfatiza a prática estratégica, tornando-se assim pós-processual (CHIA; MACKAY, 2007), por priorizar essa lógica decorrente da prática em si ao invés de se ater ou ter como foco central os atores e agentes JOHNSON et al, 2007).

Nesta via, atentou-se ao processo de estabelecer ou criar a estratégia partindo-se da abordagem prática, compreendendo que a estratégia emerge a partir da interação das pessoas, compreendendo que: "As such, Strategy as Practice is essentially concerned with strategy as activity in organizations, typically the interaction of people, rather than strategy as the property of organizations" (JOHNSON et al, 2007, p. 3). A S-as-P passa a ter foco no 'o que as pessoas fazem', sendo necessário também compreender seu contexto organizacional e institucional. $\mathrm{O}$ conceito-chave dentro desta perspectiva é a 'prática', conceito este debatido deliberadamente sem uma abordagem unificada ou uma definição consensualmente aceita. Restringindo este trecho a uma visão, sem propiciar o debate do conceito, apresenta-se a visão de Johnson et al (2007), na qual a prática é constituída por procedimentos institucionais, sistemas, ferramentas e técnicas, recorrente na rotina da organização. Na proposta de Whittington (2006), a prática está relacionada com a práxis e os praticantes, no qual a práxis é a conexão dos aparatos ferramental, técnico e institucional com a ação implicada pelo sujeito - o praticante - dentro do campo social (JARZABKOWSKI; BALOGUN; SEIDL, 2007). A práxis também pode ser compreendida como um comportamento ainda não rotinizado ou algo entre um antigo e um novo comportamento (JOHNSON et al, 2007) e como uma performance adaptativa ou improvisada (WHITTINGTON, 2006)

À medida que o observador se aproxima da razão prática da estratégia, percebe a importância das pessoas envolvidas no processo, pois a estratégia é planejada, desenvolvida e implementada por pessoas (WHITTINGTON, 2004). Nesse sentido, entender a estratégia como prática social é admiti-la como uma atividade situada e realizada de forma interativa, bem como construída mediante ações e interações dos múltiplos atores envolvidos na realização da prática estratégica, quer estejam na formulação ou execução da mesma (JARZABKOWSKI, 2005). Portanto, para um estudo que conceba a Estratégia Como Prática - S-as-P, deve haver um enfoque simultâneo nos Praticantes, nas Práticas e nas Práxis, que compõem a estratégia da organização, bem como suas mútuas conexões (WHITTINGTON, 2004; JARZABKOWSKI, 2005).

Sob esse argumento, o processo de estratégia como prática ocorre justamente na sobreposição de três dimensões de análise: os Praticantes, as Práticas e as Práxis (JARZABKOWSKI, 2005; WHITTINGTON, 2004). Em outras palavras, os resultados da estratégia na ação são resultantes da interação entre essas três dimensões. Dessa forma, conclui-se que de acordo com a abordagem da SAP, os Praticantes constituem um fator importante para o entendimento do processo social de construção da estratégia. Tal relevância se deve à compreensão do seu significativo impacto sobre o desempenho e sobrevivência da estratégia. Por conseguinte, para se entender como a estratégia é desenvolvida, se faz necessária a compreensão de características pessoais dos Praticantes, tais como, o viés perceptivo do contexto, o modo como agem, e quais Práticas fazem uso. 
Nessa perspectiva, a estratégia é algo que os Praticantes realizam e não algo que as organizações possuem. Dessa forma, aquela emerge mediante a atividade gerencial, realizada por agentes de alto conhecimento, que se esforçam rotineiramente em algo analítico, formal e sistemático, e o fazem em um ciclo de planejamento estratégico (WHITTINGTON, 2004). Os Praticantes são aqueles atores que fazem uso das Práticas para a ação e produção das Práxis. Em outras palavras, são os Praticantes que utilizam as Práticas que prevalecem e estão em curso mediante a adaptação, combinação e coordenação em vista das necessidades de uso. Em consequência, essas Práticas, formadas intencionalmente ou não, se institucionalizam em novas Práticas resultantes (WHITTINGTON et al; 2007; JARZABKOWSKI; BALOGUN; SEIDL, 2007).

Assim sendo cabe destacar, dois pontos relevantes concernentes a essa pesquisa: (1) a partir do fluxo de atividades, das práticas e dos atores organizacionais, em especial mediante os relatos dos gestores nacionais e dos superintendentes regionais, busca-se saber quais percepções dos gestores policiais de como se deu o processo do fazer estratégico na PRF, ; (2) fica evidente que essa abordagem sobre estratégia foge do mainstream dos estudos estratégicos, que estão mais direcionados para um viés ou uma lente mais funcionalista. A abordagem da estratégia como prática o entendimento é que a estratégia é construída ou é estruturada a partir da interação de sujeitos que possuem diversidade de costumes, culturas, e ideologias, sendo, portanto, as abordagens metodológicas que melhor se adequariam a essa abordagem, a construtivista e a interpretativista (OKAYAMA et al, 2014), ponto a ser aprofundado na seção 3. Procedimentos metodológicos.

\section{Procedimentos Metodológicos}

No contexto desse estudo a visão de mundo adotada como paradigma é o construtivismo. Ao utilizá-lo para estudar questões relacionadas com a compreensão da vida humana em suas especificidades, o construtivismo abre espaço para a interpretação do investigador sobre os fenômenos. Investigações alicerçadas sobre o paradigma construtivista tem um foco naturalista e interpretativo da realidade (GUBA, LINCOLN, 1994; PAIVA, MELLO, 2008). Construtivistas argumentam que os indivíduos constroem significado sobre a realidade em que vivem. A partir dessa perspectiva, as pessoas desenvolvem entendimentos subjetivos sobre as suas experiências, e estes são múltiplas e variadas interpretações. O objetivo de pesquisa é explorar o significado dos vários significados que as pessoas atribuem ao mundo (CRESWELL, 2010).

Assim, este estudo seguiu uma linha interpretativa. A pesquisa interpretativa assume que a realidade não é apenas perceptível, mas socialmente construída. Assim, o mesmo fenómeno pode ser compreendido de várias maneiras. A partir desta perspectiva, o conhecimento não vem do pesquisador, mas é construído pelo pesquisador a partir da observação e interação no contexto estudado (MERRIAM, 2009). Adotou-se assim uma visão subjetiva, em que os resultados foram construídos a partir da interpretação da realidade estudo (GUBA, LINCOLN, 1994). Neste sentido, buscou-se uma abordagem hipotético-dedutiva, não obstante uma certa abertura à alguma forma de indução, com base no método qualitativo. A pesquisa qualitativa é um conceito amplo, que abrange várias formas de pesquisas que auxiliam na compreensão e explicação o significado de um fenómeno social, não obstante as perturbações do ambiente natural (MERRIAM, 2009).

Por sua vez, o método etnográfico, que se alicerça sobre a coleta de dados, primária e secundária, em uma comunidade, ou em um grupo específico, objetiva conhecer seus estilos de vida, sua cultura específica, hábitos, estilos, formas de comunicação, entre outras características idiossincráticas (CAVEDON 1999, 2003, 2014). Tratase um trabalho personalizado, comumente realizado por pesquisadores em convivência constante com as pessoas do grupo ou comunidade estudados, tornando-os co-participantes e observadores das realidades pesquisadas, num período que pode variar de algumas semanas a alguns anos (CAVEDON, 1999, 2003, 2014; ANGROSINO, 2009; FIGUEIREDO, CAVEDON, 2012). Também é dialógico, considerando que as conclusões e interpretações podem ser discutidas com os informantes na proporção em que a experiência etnográfica é construída (ANGROSINO, 2009).

Conforme informado no início da seção, o conhecimento é construído, nesse caso co-construído, na medida em que considera a perspectiva do outro, e cabe ao pesquisador procurar compreender as crenças, valores e significados que sustentam a vida das pessoas em seu grupo ou comunidade (CALIMAN, COSTA, 2008; FIGUEIREDO, CAVEDON, 2012). Para isso, deve-se estar no campo, e interagir com as pessoas que lá se encontram, como forma de viabilizar a entrada do pesquisador nos eventos cotidianos, permitindo que ele participe em situações incomuns a outros grupos e, eventualmente extemporâneas (OLIVEIRA, CAVEDON, FIGUEIREDO, 2012; CHIESA, FANTINEL, 2014). Para isso, é necessário construir a relação de confiança entre pesquisador e pesquisado, a qual decorre, em última instância, da própria interação, assim como da sensibilidade, personalidade e comportamentos éticos do pesquisador, que vão além do lado intelectual e sua capacidade técnica (VAN MAANEN, 1984; CAVEDON, 2014; OLIVEIRA, CAVEDON, FIGUEIREDO, 2012; CHIESA, 
FANTINEL, 2014).

Destaca-se ainda questão de natureza ética, uma vez que o autor principal faz parte da instituição, e isto poderia, de alguma forma, limitar ou restringir os possíveis achados, ou ainda, de alguma se restringir à divulgação dos mesmos. Enfatiza-se, entretanto, que o trabalho de campo etnográfico é um ato de equilíbrio entre distância e imersão e que os trabalhadores de campo precisam abordar para compreender de forma significativa os esforços de sensação dos pesquisados. Em livros metodológicos sobre etnografia, a imersão tende a ser enfatizada à custa de sua contraparte. De fato, o "desapego" é muitas vezes ignorado como um princípio central da boa conduta etnográfica (DE JONG, KAMSTEEG, YBEMA, 2013). Tietze (2012), por exemplo, destaca alguns aspectos importantes, como a relação do pesquisador e pesquisa, reflexividade e ética. Para o pesquisador, os grandes desafios relacionados a esses três aspectos são a busca pela imparcialidade devido ao envolvimento emocional com a organização e as pessoas e para tornar o "normal" algo "estranho" no primeiro momento e, em um segundo momento, presente o "estranho" como "normal". Um segundo tópico é que todas as instituições desenvolvem um conjunto de presunções que, é claro, não são objeto de conhecimento para aqueles que estão fora de seu domínio, e este é o caso dos etnográfos das organizações. Ou seja, ser parte da organização (FINE, SHULMAN, 2009) e desta forma, o etnógrafo organizacional deve conquistar dois planos: (1) os requisitos inerentes ao estudo de uma Organização e (2) atender às expectativas de um pesquisador etnográfico. Conciliar esses planos pode produzir dilemas morais práticos, que podem se relacionar com o uso adequado do pleno consentimento informado, o gerenciamento de impressões enganosas e a necessidade de omitir informações relevantes no material publicado (FINE, SHULMAN, 2009, DE JONG, KAMSTEEG, YBEMA, 2013). A ingenuidade e a falta de reflexividade na etnografia organizacional podem gerar situações desagradáveis, e é importante levar em consideração isso não somente no trabalho de campo, mas principalmente nas análises, nos achados, nas implicações e na divulgação da pesquisa (FINE, SHULMAN, 2009; DE JONG, KAMSTEEG, YBEMA, 2013).

\subsection{Delineamento da Pesquisa}

Inicialmente, a pesquisa ocorreu por meio de fontes secundárias, mais precisamente por meio dos relatórios de gestão da PRF referente ao ano de 2014 (Brasil, 2015:115). Soma-se a esse documento oficial um outro que foi planejamento estratégico da PRF (BRASIL, 2014), que só foi publicado no início de 2014 e mesmo assim as metas em relação aos indicadores relativos à Segurança nas Rodovias Federais foram atingidas. Destacando-se ainda que, num momento em que a quantidade de acidentes e mortes no trânsito no Brasil tem crescido na última de década, no país como um todo (OLIVEIRA, 2016), nas rodovias federais o número de acidentes e de mortes no trânsito reduziu contrariando o que ocorre no resto do país (BRASIL, 2015).

Após o acesso aos dados secundários, em razão do estabelecimento desde janeiro de 2017, chefes, gestores e comitês de gerenciamento foram envolvidos no processo de transição de gestão e de ajuste do orçamento, devido à mudança da direção geral e à forte restrição orçamentária imposta pelo governo federal. Esses grupos de trabalho basearam suas ações em reuniões diárias para avaliar os resultados reais em relação ao planejamento estratégico formulado e implementado desde 2014 até o final de 2016, pela gestão anterior. Além disso, foram incumbidos de fazer uma anamnese organizacional com base neste estudo. As reuniões foram embasadas nos relatórios de gerenciamento policial, planejamento estratégico e relatórios de transição de gestão, elaborados no primeiro semestre de2017. Estes documentos gerados também foram utilizados como fontes secundárias de dados para a pesquisa. Inicialmente, a pesquisa documental foi utilizada como uma forma de triangular as informações coletadas por meio das fontes primárias, a saber: entrevistas semiestruturadas e observações participantes.

As fontes primárias de dados, foram entrevistas e observação participante, realizadas com base numa amostra intencional. Este tipo de amostra é o mais adequado a essa pesquisa, uma vez que ao acesso a esses respondentes da amostra intencional, pode convergir para melhor esclarecer a resposta à pergunta de pesquisa, na medida em que essas são as pessoas melhor conhecem a realidade que se pretende investigar (MILES, HUBERMAN, 1994). Especificamente, nesse estudo, optou-se por um caso extremo em amostra intencional, que corresponde aos gestores policiais nacionais ou gestores policiais regionais, todos eles responsáveis pela implementação de estratégia em seu macroambiente. Na realidade PRF, eles têm um total de 07 gerentes nacionais e 27 superintendentes. A nível nacional existe 01 diretor e 06 coordenadores nacionais, da seguinte forma: operações, administrativas e financeiras, tecnologia e modernização, assuntos internos, inteligência e recursos humanos. Em cada estado da federação existe o gerente local, o superintendente, que corresponde ao diretor, no entanto, a nível regional ou estadual. Por outro lado, desses 34 potenciais participantes da pesquisa, 22 deles são gerentes nacionais ou superintendentes desde 2014, embora alguns deles tenham mudado sua área ou função. Em outra perspectiva, foram criados comitês de transição e planejamento estratégico, nos quais outros nove outros gerentes e superintendentes nacionais são membros, ou seja, policiais que participaram do processo de implementação 
estratégica e não mais diretamente vinculados à administração, embora sejam Como funcionários no processo. $\mathrm{O}$ diretor da PRF autorizou os pesquisadores a seguir todo esse ciclo de reuniões ocorrido de fevereiro a maio de 2017, em Brasília. Portanto, foram realizadas entrevistas semi-estruturadas com 15 dos 22 gerentes e superintendentes nacionais que participaram do processo de estudo e permanecem na administração e pelo menos 06 dos 09 policiais que participaram e não estão mais ligados diretamente à atual gestão. A ideia desses dois grupos é perceber se existem ou não diferentes perspectivas e pontos de vista porque as pessoas permanecem no "sistema", ampliando assim a possibilidade de entender o evento como um todo.

Como observação participante, fez-se a opção por uma observação ativa, que implica no pesquisador adquirir uma posição dentro do grupo de estudo desempenhar um papel neste grupo, entretanto, ao mesmo tempo, manter uma certa distância do mesmo (ADLER, ADLER, 1987). Ainda de acordo com esses autores, é importante que este participante evite provocar mudanças, ou evite apresentar seus valores na situação, mas ainda mantendo comprometido e implicado. Durante esses ciclos de reuniões, foi realizada observação participante em 28 das 36 reuniões dos comitês de transição.

Em fevereiro de 2017, duas entrevistas pilotos foram realizadas, uma com um gestor que participou do processo de estratégia e ainda continua na gestão e outro que também participou do processo, contudo, não mais permanece na gestão. Por meio dessas entrevistas, detectou-se a necessidade de uma melhor adequação da linguagem, mais especificamente de torná-la menos acadêmica e mais próxima à realidade que se pretendia investigar. Além disso, cabe ressaltar a receptividade por parte de todos os gestores, uma vez que, a despeito das obrigações, das responsabilidades e das atribuições às quais estes estão sujeitos, todos eles demonstraram um forte interesse em serem ouvidos, em apresentarem a realidade com a qual se defrontam, e, acima de tudo, que através das opiniões deles, seja possível prover algo de mais efetivo, relevante e pragmático à instituição.

\section{Resultados e Análise dos Dados}

A apresentação dos resultados e das análises está resumida na figura 01 abaixo:

Figura 01: Mapa de apresentação dos resultados e análise dos dados

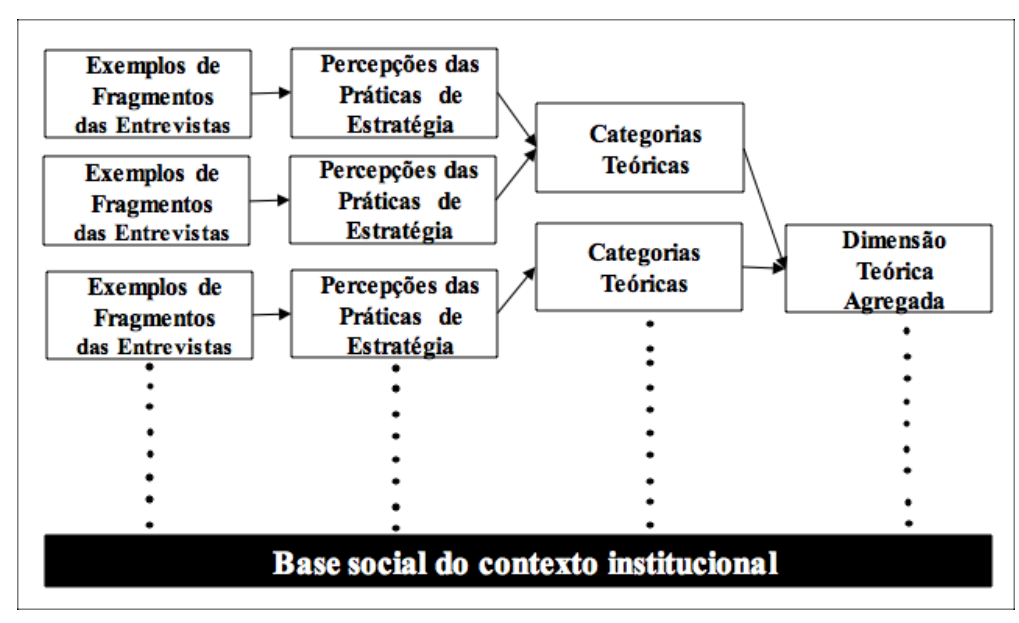

Fonte: elaborado pelos autores.

De acordo com a figura 01 acima, a partir da base social do contexto a ser pesquisado é que se desenvolve todo o processo de estratégia como prática (WHITTINGTON, 2004; JARZABKOWSKI, 2005; JOHNSON et al, 2007). Isto posto, a apresentação dos resultados e das análises inicia com a questão contextual e, posteriormente, discorrerse-á sobre a codificação, a formação das categorias e sobre a convergência daquelas para a explanação da percepção dos gestores da PRF, sobre o processo de implantação da estratégia como prática, na respectiva instituição, no período de 2014 a 2016.

A seguir apresenta-se a figura 02 , que resume a perspectiva contextual e social da instituição pesquisada, a qual alicerça todo o processo de da estratégia como prática. Cumpre destacar que a própria compreensão do contexto policial institucional já se enquadra como o início da percepção da segurança cidadã, uma segurança que não é um fim em si mesmo, todavia, que visa garantir o exercício de direitos, o atingimento do bem comum de forma contextualizada (PIRES, WANDERLEY \& HORTON, 2015). Em outras palavras, a segurança cidadã se limita ao combate à violência, entretanto, parte do reconhecimento das liberdades, dos direitos e dos contextos sociais das pessoas, sejam cidadãos ou representantes do Estado. Assim sendo, somando-se ao caráter qualitativo da pesquisa a apresentação da figura 02 contribui tanto para a compreensão contextual, quanto para o entendimento das 
percepções dos gestores, a serem analisadas mais à frente.

Figura 02: Análise da base social contextual da pesquisa

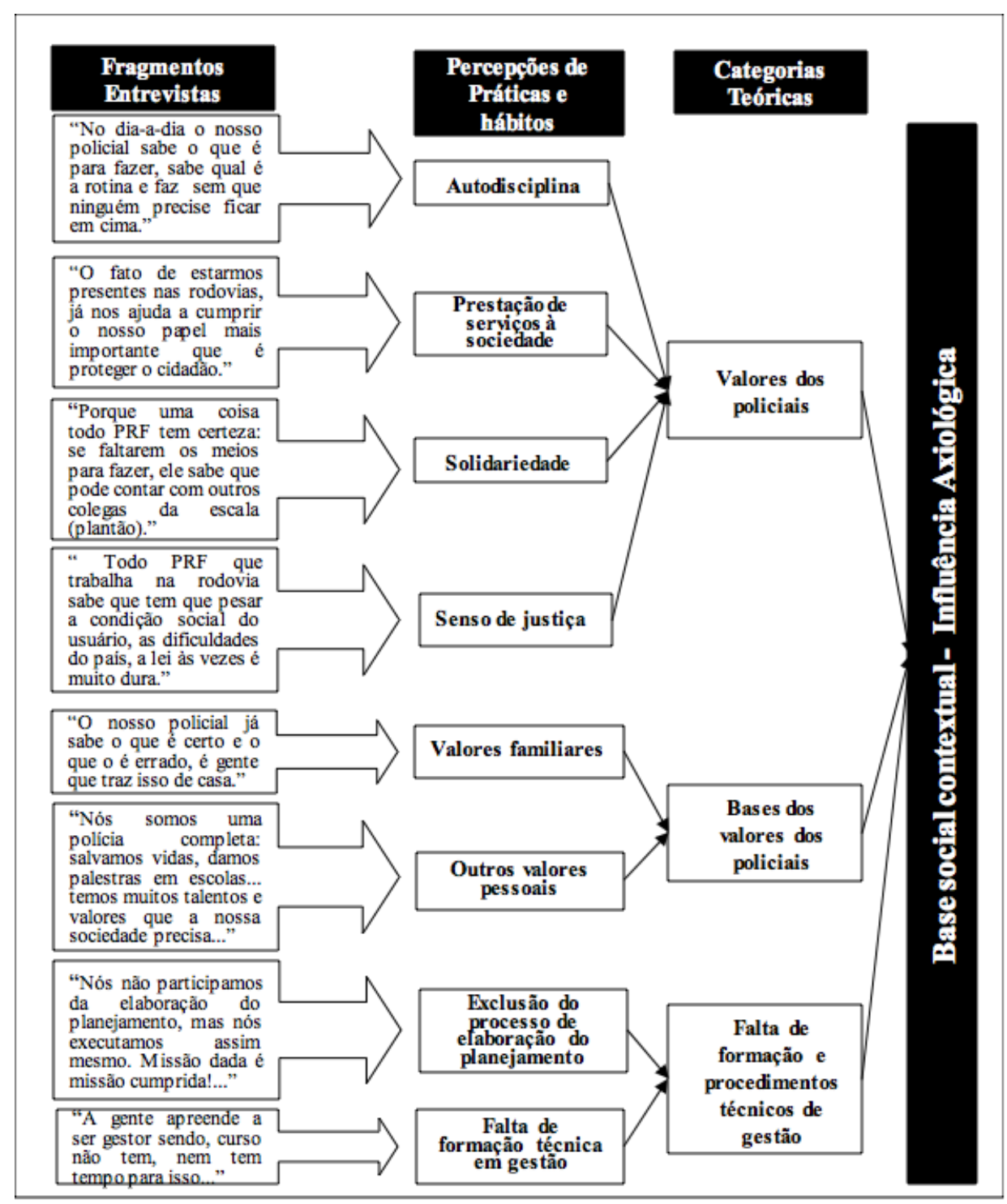

Fonte: elaborado pelos autores.

Depreende-se da figura 02 que o contexto pode ser apresentado por meio de 03 categorias teóricas resumo, a saber: (1) valores dos policiais, (2) base dos valores dos policiais e (3) a falta de formação e de procedimentos técnicos em gestão. A categoria (1) valores dos policiais relaciona-se a valores compartilhados consciente ou inconscientemente pelos agentes da PRF, são elementos tácita e socialmente, não só aceitos, todavia, efetivamente presentes. A segunda categoria - base dos valores dos policiais, também diz respeito aos valores, todavia, às outras possíveis fontes de valores, que não sejam clara e exclusivamente pessoais e compartilhados, a exemplo de valores familiares, valores cívicos entre outros. Não obstante no início das entrevistas e observações, havia uma possível fonte clara de geração de valores associada ao ensino da instituição, ficou patente que a família seria uma fonte de valor relevante.

As demais possíveis fontes - legislação, ensino, a instituição em si, de maneira indistinta, são, de alguma maneira, condicionantes de valores, contudo, não foi possível identificar claramente algum maior destaque contextual, a exemplo do corrido com a família. Importa destacar que, essa influência dos valores, que constam na base contextual, são o alicerce, são as lentes tanto para as percepções dos gestores, tanto quanto para a estruturação dos hábitos e costumes dentro da organização. Além disso, por serem características basilares do contexto, passam a compor seu cotidiano, com a tendência de se manter ao longo do tempo, mesmo em casos de mudanças. 
Por fim, no que tange à estruturação contextual, destaca-se a categoria (3) - a falta de formação e de procedimentos técnicos em gestão, a qual diz respeito a uma não formação técnica dos gestores para exercer usas atividades. $\mathrm{O}$ que há princípio achava-se fazer parte do processo de estruturação formal da estratégia, por fim, levantou-se que estava ausente do processo como um todo, o que permite antecipar que essa lacuna será compensada mais à frente, por meio da práxis, uma vez que essa diz respeito à improvisação, à adaptação de práticas perante novas situações, a novos comportamentos (WHITTINGTON, 2004; JARZABKOWSKI, 2005; JOHNSON et al, 2007).

Antes de apresentar a figura 03, a qual apresenta a visão geral das análises, destaca-se que emergiram duas categorias teóricas que vão auxiliar a responder à pergunta de pesquisa, relativa às percepções dos gestores da PRF diante do Plano Estratégico 2013-2020, quais sejam: (1) cultura de coesão social e (2) hábitos e costumes que garantem a cultura organizacional. Cumpre destacar que essas categorias não correspondem especificamente a recursos organizacionais, ou a algo que a instituição possua, porém, a práticas reiteradas identificadas em seu âmbito (SCHATZKI, 2005; JARZABKOWSKI ET AL., 2007; VAARA \& WHITTINGTON, 2012; SEIDL \& WHITTINGTON, 2014). Não obstante essas práticas emerjam dos praticantes o foco não se volta a esses, mas, às práticas em si, entretanto, não se abordou as práticas como recursos, todavia, como formas de interação social que, nesse caso específico, conduziram e geraram à implementação estratégica (CHIA; MACKAY, 2007; JOHNSON et al., 2007). Além disso, são essas categorias que vão influenciar no processo de S-as-P em dois pontos específicos, a saber: (1) a recursividade e (2) efetividade na implementação. A recursividade (1) diz respeito a dinâmica no processo estratégico, advinda da atividade prática (JARZABKOWSKI 2005). Segundo a autora, a S-as-P lastreiase em recursividade e adaptação, uma vez que a mesma entende a estratégia como uma interação reflexiva entre agente e estrutura, tornando a prática social um processo rotineiro e institucionalizado na organização. A efetividade na implementação (2) diz respeito à prática social voltada à implementação da estratégia, consciente ou não, e recursiva ou não. De acordo com Whittington (2004), a perspectiva da estratégia como prática, diz respeito às práticas que envolvem a elaboração de estratégias como: discussão de ideias, de oportunidades, apresentação de cenários, assim como as ações de planejamento, formulação de estratégia, a escrita de documentos formais, realização de apresentações, reuniões, conversas, preenchimento de formulários, no qual levam a estratégia ser realmente formulada e implementada. Portanto, para o autor, tanto a habilidade técnica como artesanal, bem como o conhecimento tácito e o formal, local e geral, são elementos importantes nesta perspectiva.

A seguir apresenta-se uma visão geral das análises realizadas a partir do levantamento primário de dados, triangulado com os dados secundários, a saber:

A categoria (1) - cultura de coesão social - emergiu uma vez que as práticas de convivência policial em nível nacional foram mencionadas por diversos gestores e superintendentes a partir de um certo momento das observações participantes, dessa forma buscou-se aprofundar essa prática no momento das entrevistas. Essa categoria teórica mais ampla, a qual se refere à cultura de coesão social, foi estruturada a partir da identificação de práticas e hábitos presentes na instituição, evidenciados em diversos diálogos e práticas, a exemplo: (i) proximidade dos policiais com a gestão; (ii) interação com outros policiais da PRF tanto em nível local, quanto nacional; (iii) interação com policiais e outras corporações tanto em nível local, quanto nacional; (v) interação constante com outros órgãos de fiscalização e controle tanto em nível local, quanto nacional. Antes de tudo, cumpre destacar que, essa categoria que emergiu das percepções dos gestores, corresponde a práticas e hábitos reiterados de trocas de informações e de formações, não obstantes informais, entretanto, que efetivamente favorecem a estruturação e padronização de ações e de práticas local e nacionalmente. Ressalta-se ainda que, essa coesão social está relacionada a um potencial de unissonicidade de objetivos e ações, ainda que não formal, todavia, efetiva.

A categoria (2) - hábitos e cultura costumes que garantem o estilo de gestão - são socialmente construídos com base nas relações entre os diversos policiais de diversos locais que, por sua vez, são influenciadas forjam os valores e os princípios da PRF, com base na influência axiológica, destacada na figura 02. Esses hábitos e costumes retroalimentam a gestão, na medida em que mesmo na ausência de diretrizes, normas e supervisão, as ações e as práticas ocorrem como se a gestão estivesse presente ou se houvesse determinação dessa para tais fins. A categoria hábitos e costumes que retroalimentam a abordagem de gestão foi caracterizada pelas seguintes propriedades: (i) práticas de colaboração entre os policiais e gestores e vice-versa; (ii) tipo de atividade; (iii) descentralização; (iv) ensino de tarefas com o apoio ao aprendizado; (v) responsabilidade; (vi) comprometimento com a entrega de resultados. O que ocorreu de fato não só nas entrevistas, mas também, durante as observações participantes é que diversos fatos, decisões foram apresentados e citados como se emanassem de alguma diretriz ou de algum gestor, até pelo fato de coadunarem com princípios legais, normativos e éticos. Entretanto, essas situações eram, de fato, capitaneadas e de responsabilidade dos policiais que se encontravam na situação real, concreta e eminente, todavia, agiram lastreados em suas influências axiológicas, sem se distanciar dos princípios e diretrizes da gestão, mesmo que sem os conhecer formalmente. 
Figura 03: Visão geral das análises

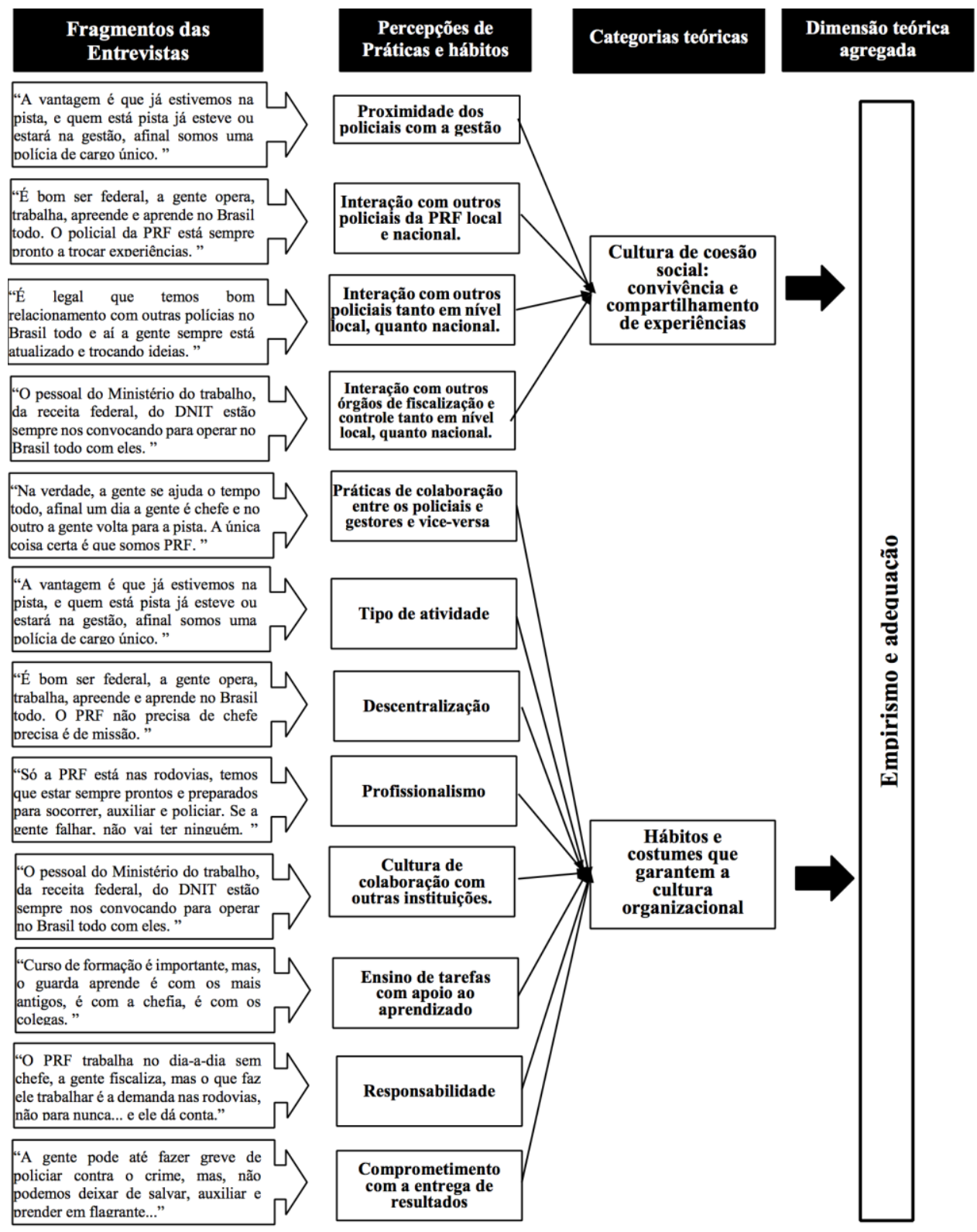

Fonte: elaborado pelos autores.

A dimensão teórica agregada foi o empirismo e a adequação, não obstante a pesquisa tenha sido realizada numa instituição pública. Se, por um lado, há diversos regramentos jurídicos e documentos como base para as práticas e decisões, como é peculiar para toda instituição pública, por outro, o que prevalece como prática, e que de fato constitui a abordagem de gestão é a própria interpretação e adequação de cada gestor ao planejamento. A forma de conduzir o cotidiano da coordenação geral, superintendência ou distrito, é traduzida por meio das subcategorias encontradas, a saber: (i) adequação segundo os próprios valores; (ii) adequação segundo à natureza da atividade; (iii) adequação conforme valores compartilhados e (iv) adequação segundo a resposta dos stakeholders. O que se torna interessante é que, não obstante em todas as entrevistas e observações haja citações ao planejamento formal, nas práticas e no aprofundamento dos temas e dos fatos, há, quase que invariavelmente, decisões e práticas realizadas e adequadas conforme os valores acima.

\section{Considerações Finais}

O presente estudo foi guiado pela pergunta principal: "quais as percepções dos gestores da PRF diante do Plano Estratégico 2013-2020?", e nesse sentido, buscou-se compreender o processo de construção dessas percepções desde seu contexto, por meio do método etnográfico. O referido método foi empregado em razão de uma instituição 
de segurança pública, que atua em nível nacional, tem modo próprio de existir e de ser. Além disso, trata-se de um ambiente complexo, que atua numa seara sensível, pouco permeável, de difícil inserção, fatos que convergiram para que o método etnográfico se mostrou adequado, na medida em que o pesquisador se torna uma partícipe nesse ambiente, nesse contexto.

Como resposta ao questionamento acima, as percepções indicaram que houve um processo de adequação e de empirismo em relação ao planejamento original, entretanto, o que se tem de incremental no campo teórico são os caminhos percorridos para que essas percepções se formassem, no contexto específico.

A cultura de coesão social possui os elementos relevantes para a construção social dos meios que constituem a gestão e a implementação estratégica na PRF. Os gestores policiais assumem assim, o papel daquele que interpreta, age e promove a interação tanto entre os próprios colegas de instituição, quanto entre outros stakeholders para construir e manter a gestão policial alinhada com a entrega à sociedade e às outras instituições. São eles que motivam e articulam recursos e pessoas, gerando resultados, ações, adequações sob um prisma de interrelação. A cultura de coesão, bem como a experiência coletiva que ela pressupõe, é construída com base no foco da própria essência de uma instituição de prestação de serviços de segurança pública, voltada para a segurança cidadã. De fato, se torna cultura quando encontra adesão dos policiais e se manifesta também na comunicação, na troca de experiências e na ajuda mútua entre as superintendências e coordenações internamente, e com outras instituições afins, externamente.

Os hábitos e os costumes que garantem a cultura organizacional são construídos por influência contextual, nomeadamente no que tange aos valores dos policiais e à base dos valores dos policiais. Esse conjunto axiológico estruturante, que permeia a PRF, é uma das bases fundamentais para garantir a manutenção dos hábitos e costumes da cultura organizacional. Por outro lado, e não menos relevante, quando se observa a inserção dos stakeholders nesse contexto, há uma dinâmica de reciprocidade que passa a caracterizar o clima organizacional, bem como os relacionamentos externos.

A dimensão teórica agregada o empirismo e a adequação que, em última instância, responde à pergunta, emergiu dos dados de maneira peculiar e estreitamente relacionada às categorias anteriores. Os valores dos policiais, a cultura de coesão e, os hábitos e costumes que garantem a cultura organizacional não só influenciam suas interpretações sobre a estratégia organizacional, mas também condicionam as adequações e implementações efetivas. Então a percepção é que a S-as-P passa a ser, na PRF não algo que ela apenas adota, todavia, algo em que se torna. Esse tornar, entretanto, ocorre em razão das práticas, das experiências, das ideias compartilhadas e não por meio de discursos ou normas impostas.

Por fim, ressalta-se que um dos objetivos subjacentes do artigo, conforme destacado anteriormente, é sair um pouco do mainstream dos estudos sobre segurança pública, e pesquisar o tema num viés da percepção dos atores e, consequentemente seus valores e ideias. Sentir-se seguro é um dos exemplos mais significativos e claros de direitos humanos fundamentais e um pré-requisito para a realização e o gozo de qualquer outro direito. Ao conectar o policial e sua gestão, enquanto partícipe ativo e responsável do processo de segurança cidadã, enfatizam-se princípios como a participação, a responsabilização e a promoção dos direitos humanos. A abordagem da segurança cidadã, como uma abordagem baseada em valores, com foco em conceitos como responsabilidade, transparência, igualdade e justiça social, almeja contribuir para organizar assuntos sociais e acelerar um desenvolvimento mais eficiente.

\section{Referências}

ADLER, P. A.; ADLER, P. Membership roles in field research. Sage, 1987.

ANGROSINO, M. Etnografia e Observação Participante. Porto Alegre: Artmed, 2009.

BRASIL. Polícia Rodoviária Federal. Portaria n 28, de 12 de fevereiro de 2014. Institui o Plano Estratégico da Polícia Rodoviária Federal para o período 2013-2020, 2014.

BRASIL. Polícia Rodoviária Federal. Relatório de gestão do exercício de 2014. Brasília- DF, 2015. Disponível em: https://www.prf.gov.br/portal/estados/sede/prestacao-de-contas/2014-relatorio-de-gestao. Acesso em: $08 \mathrm{de}$ Março de 2017.

CALIMAN, N. F.; COSTA, R. R. C. C. Os Desafios da Pesquisa Etnográfica na Administração: uma análise a partir de artigos publicados de 1998 a 2007. In: XXXII Encontro da ANPAD, Rio de Janeiro, 2008.

CAVEDON, N. R. O método etnográfico em estudos sobre a cultura organizacional: implicações positivas e negativas. In: XXIII Encontro da ANPAD, Rio de Janeiro, 1999 
CAVEDON, N. R. Antropologia para administradores. Porto Alegre: UFRGS, 2003

CAVEDON, N. R. Método Etnográfico: da Etnografia Clássica às pesquisas contemporâneas. In: SOUZA, E.M. (org.). Metodologias e Analíticas Qualitativas em Pesquisa Organizacional: Uma abordagem teóricaconceitual. Vitória: EDUFE, p. 65-90, 2014.

CHIESA, C. D.; FANTINEL, L. D. "Quando eu vi, eu tinha feito uma etnografia": notas sobre como não fazer uma "etnografia acidental". In: VIII Encontro de Estudos Organizacionais da ANPAD, Gramado/RS, 25 a 27 de maio de 2014.

CIDH. Informe sobre seguridad ciudadana y derechos humanos. Washington, D.C.: BID, 2009. Disponível em: https://www.cidh.oas.org/pdf\%20files/SEGURIDAD\%20CIUDAD ANA \%202009\% 20ENG.pdf. Acesso em: 19 de mar. 2017.

COURPASSON, D; MONTIES, V. "I Am My Body". Physical Selves of Police Officers in a Changing Institution. Journal of Management Studies, v. 54, n. 1, p. 32-57, 2017.

DE JONG, M.; KAMSTEEG, F.; YBEMA, S. Ethnographic strategies for making the familiar strange: Struggling with 'distance'and 'immersion'among Moroccan-Dutch students. Journal of Business Anthropology, v. 2, n. 2, p. 168-186, 2013.

FINE, G. A.; SHULMAN, D. Lies from the field: Ethical issues in organizational ethnography. Organizational ethnography: Studying the complexities of everyday life, p. 177-195, 2009.

FREEDMAN, M. The genius is in the implementation. Journal of Business Strategy. Mar./Apr., 2003, p. 26-31.

FIGUEIREDO, M. D.; CAVEDON, N. R. Com Açúcar, com Afeto? A Profissionalização do Fazer Amador de Doces Artesanais de Pelotas. In. Revista interdisciplinar de gestão social/ Universidade Federal da Bahia, Escola de Administração, Centro Interdisciplinar de Desenvolvimento e Gestão Social. v. 1, n. 3 (set/dez. 2012) -Salvador: EAUFBA, 2012.

GUBA, E.; LINCOLN, Y. Competing paradigms in qualitative research. In: DENZIN, N; LINNCOLN, Y. (ed.). Handbook of qualitative research. Thousand Oaks: Sage, 1994. p. 105-117.

JARZABKOWSKI, P. Strategy as practice: an activity-based approach. California: Sage, 2005.

JARZABKOWSKI, P.; BALOGUN, J.; SEIDL, D. Strategizing: the challenges of a practice perspective. Human Relations, v. 60, n. 1, p. 05-27, 2007.

KARPIAK, K. No longer merely "good to think": The new anthropology of police as a mode of critical thought. Theoretical Criminology, v. 20, n. 4, p. 419-429, 2016.

MERRIAM, S. B. Qualitative research: a guide to design and implementation. San Francisco: Jossey-Bass, 2009. MINTZBERG, H. Primeiro pense, primeiro veja, primeiro faça. HSM Management, v. 69, 2008.

OKAYAMA, E.; GAG, M.; OLIVEIRA JUNIOR, P. F. P. Análise da produção científica em estratégia como prática. Revista Brasileira de Estratégia, v. 7, n. 2, p. 191-204, 2014.

OLIVEIRA, J. S. ; CAVEDON, N. R.; FIGUEIREDO, M. D. O Artesanato na Ótica de Quem o Produz: Com a Palavra os Artesãos do Brique da Redenção em Porto Alegre. Revista interdisciplinar de gestão social/ Universidade Federal da Bahia, Escola de Administração, Centro Interdisciplinar de Desenvolvimento e Gestão Social. V. 1, n. 3 (set/dez. 2012)-Salvador: EAUFBA, 2012.

OLIVEIRA, A. M. ONU: década de ações para a segurança no trânsito 2011-2020. 2016.

PARES, A.; VALLE, B. A retomada do planejamento governamental no Brasil e seus desafios. In: GIACOMONI, J.; PAGNUSSAT, J. L. (Org). Planejamento e orçamento governamental. coletânea. Brasília: ENAP, v. 1, p. 229-270, 2006.

PAIVA, F. G.; MELlO, S. C. B. Pesquisa Qualitativa nos Estudos Organizacionais: Contribuições Fenomenológicas de Alfred Schütz. Organizações em contexto, Ano 4, n. 8, dez, 2008

PIRES, D. R.; WANDERLEY, L. S. O.; HORTON, K. Desafios da Governança em Segurança Pública: da violência para a segurança cidadã. Anais do Encontro Nacional de Gestão Empresarial e Meio Ambiente (ENGEMA). São Paulo: ENGEMA USP. 2015.

PIRES, D. R. Governança em Segurança pública: mecanismos de liderança, estratégia e controle na Polícia Rodoviária Federal. 2016. 123f. Dissertação (Mestrado em Administração) - Universidade Federal de 
Pernambuco, CCSA, Recife, 2016.

RUIZ, M. C. La formación de las fuerzas de seguridad y policiales bajo el paradigma de la Seguridad Ciudadana: un desafío educativo nacional y regional. Revista Latinoamericana de Educación Comparada, v. 5, n. 5, p. 122133, 2014.

SCHATZKI, T. R. (2005). The Sites of Organizations. Organization Studies. 26(3), 2005.

SEIDL, D.; WHITTINGTON, R. Enlarging the Strategy-as-Practice Research Agenda: Towards Taller and Flatter Ontologies. Organization Studies, 1-15, 2014.

TIETZE, S. Researching your own organization. Qualitative Organizational Research: Core Methods and Current Challenges, p. 53-71, 2012.

VAARA, E.; WHITTINGTON, R. Strategy-as-practice: taking social practices seriously. The Academy of Management Annals, 6(1), 285-336, 2012.

VAN MAANEN, John. Making rank: Becoming an American police sergeant. Urban Life, v. 13, n. 2, p. 155-176, 1984.

WHITTINGTON, R. Estratégia após o modernismo: recuperando a prática. RAE - Revista de Administração de Empresas, v. 44, n. 4, out./dez. 2004.

WHITTINGTON, R. et al. Strategy as practice: research directions and resources. New York: Cambridge University Press, 2007. 